\title{
Spelling dyslexia: a deficit of the visual word-form
}

\author{
Elizabeth K Warrington, Dawn Langdon
}

\begin{abstract}
A patient with spelling dyslexia read both words and text accurately but slowly and laboriously letter by letter. Her performance on a test of lexical decision was slow. She had great difficulty in detecting a 'rogue' letter attached to the beginning or end of a word-for example, ksongor in parsing two unspaced words, such as applepeach. By contrast she was immune to the effects of interpolating extraneous coloured letters in a word, a manipulation that affects normal readers. Therefore it is argued that this patient had damage to an early stage in the reading process, to the visual word form itself.
\end{abstract}

(F Neurol Neurosurg Psychiatry 1994;57:211-216)

Dyslexia without dysgraphia, first described by Dejerine, ${ }^{1}$ can spare the ability to read aloud single letters. Patients whose letter naming is preserved typically adopt a letter by letter reading strategy, spelling the word aloud, hence the term 'spelling dyslexia' to describe this syndrome.

The very distinctive clinical syndrome, spelling dyslexia, has been the subject of numerous, detailed, single case studies. There is as yet, however, no consensus as to which subcomponent of the reading process is impaired, or even whether it represents a reading specific deficit. ${ }^{2}$

Warrington and Shallice ${ }^{3}$ published the first detailed experimental account of spelling dyslexia. They demonstrated that the time it took their patients to read a word was directly related to the word length. Two manipulations that attenuated letter by letter reading, script writing, and brief tachistoscopic presentation, resulted in further disruption to already laboured reading. Their patients appeared to have lost the ability to process letters as whole word recognition units. Warrington and Shallice suggested that their findings were consistent with damage to a presemantic lexical stage of processing, which they termed a visual word form system. This word form system they placed before both phonological and semantic analysis of the written word. Letter by letter reading was considered to be dependent on the viability of the compensatory strategy of reversed spelling.

Since this formulation there have been a number of alternative accounts of letter by letter reading. Most of these have argued for a prelexical locus of the deficit, before the access to whole word recognition units. The best articulated account of letter by letter reading as a prelexical stage in the reading process has been advanced by Patterson and Kay. ${ }^{4}$ They proposed that an intact word form system could only be accessed serially, the input from letter recognition being limited to one letter at a time. Schacter et alै provided supporting evidence by demonstrating some positive priming effects in a letter by letter reader. This, they argued, implied intact word recognition units.

Others have adopted a more radical version of the prelexical hypothesis by suggesting that letter by letter reading can be accounted for by visual impairments that are not specific to the reading process $^{67}$ notwithstanding the observation that patients with gravely impaired visual form perception may be able to read at a normal speed. ${ }^{8}$

The possibility of a more central deficit has also been advanced. Shallice and Saffran, ${ }^{9}$ and subsequently Coslett and Saffran, ${ }^{10}$ demonstrated some partial semantic knowledge of words that could not be read. This was held to implicate a post word form deficit, there being a failure to achieve a full semantic or phonological specification of the written word.

In this paper we describe a patient, with a very clear cut and selective dyslexic syndrome following a left occipitoparietal infarction. She was a letter by letter reader with intact spelling and writing. We describe four tests that manipulate the orthography of the written word. We conclude that our findings provide evidence that is consistent with damage to an early stage in the reading process, to the visual word form system itself.

\section{Patient and methods}

CASE REPORT

The patient was a 50-year-old (date of birth 23 October 1938) woman, a secretary of West Indian extraction. In 1986 a pituitary tumour was diagnosed and successfully treated surgically at the National Hospital, Maida Vale, London. In August 1988 she was re-admitted to Maida Vale Hospital, suddenly having lost the ability to read. On examination, there were no neurological signs of note other than a uniocular nasal quandrantanopia in the left eye. Acuity was normal and there was no visual field loss in the right eye. CT showed an extensive area of 
Figure CT scans showing the occipitoparietal infarction.
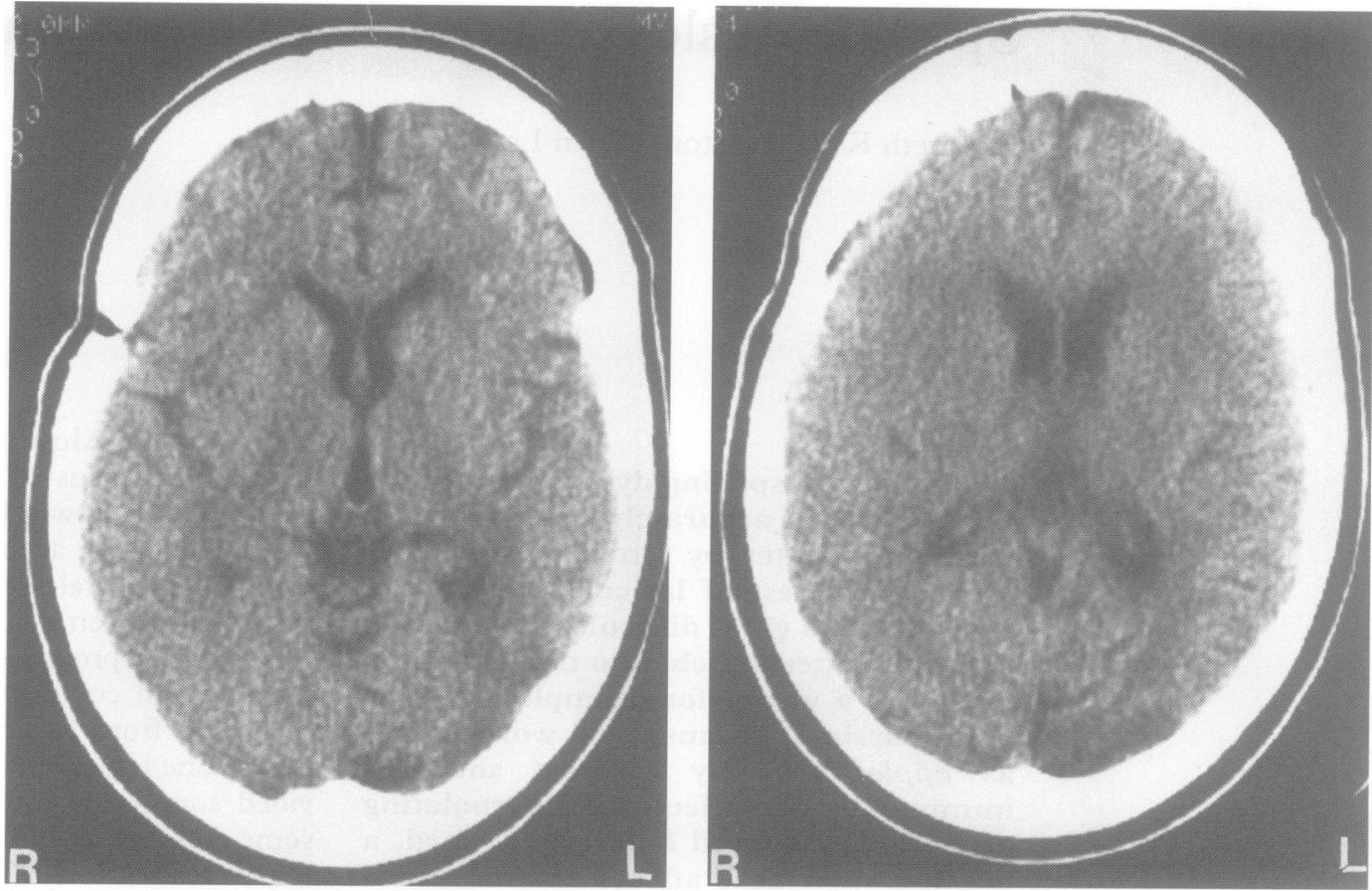

infarction in the occipitoparietal region of the left hemisphere (fig). She was treated with warfarin and she continues to be seen intermittently; the tests reported here, however, were all completed by January 1989 .

\section{NEUROPSYCHOLOGICAL ASSESSMENT}

The patient obtained a Wechsler adult intelligence scale verbal IQ of 99 and performance IQ of 69, prorated from four verbal subtests and three performance subtest scores. On a recognition memory test for faces, she obtained an average score (41/50 correct). On the verbal version of the task she obtained a low average score ( $38 / 50$ correct). On a stringent naming test, the graded naming test ${ }^{11}$ she scored at an average level (13/30 correct). She had no difficulty on an easier test of naming objects from their description (15/15 correct) ${ }^{12}$

She scored at an average level on a graded difficulty test of written spelling (set A 20/30 correct) ${ }^{13}$ Her ability to recognise words that were spelt to her was particularly impressive; she managed to identify correctly $24 / 30$ of the Baxter set B that were spelled aloud to her by the examiner. Her correct responses included 'mechanical', 'buoyant', and 'picnicking'. On a digit copying task which required her to copy six rows of 10 digits at speed, her response time of 60 seconds was at an average level for her age. ${ }^{14}$ This observation indirectly demonstrates that she can process individual visual symbols at speed.

\section{READING SKILLS}

The most striking feature of her neuropsychological assessment was that she had no viable reading. She read very slowly, apparently letter by letter. For example, she took three minutes 40 seconds to read a'oud a 35 -word sentence (making one error, flow for blow).
She read almost without error the first 10 lines of a prose passage ${ }^{15}$ but took 8 minutes 50 seconds to do so.

\section{LETTER READING}

Identification of letters presented singly was completely accurate. Her reading of single black letters flanked on either side by red letters was very satisfactory (22/23 correct), similarly she was able to read the centre target letter, underlined in a row of five (49/50 correct). Matrices of $5 \times 5$ letters were read without error. This task was replicated three times with different arrays and on each occasion her letter naming was again error free.

Twenty-four, four-letter, six-letter and eightletter words were presented singly. Half of the words of each letter length were of high frequency ( $>A$ ) and half were of lower frequency $(<A)$. The time she took to read aloud each word correctly was recorded by a stopwatch. This task was repeated at a later test session. Her performance on this task was accurate. Table 1 shows her mean reading time per word for each word length. It is clear that she read slowly and that the time to read a word increased with word length.

NON-WORD READING

Her ability to read pronounceable non-words

Table 1 Reading rates in relation to word length

\begin{tabular}{llll}
\hline & \multicolumn{3}{l}{ Mean response time $(s)^{*}$} \\
\cline { 2 - 4 } Word length & 4 & \multicolumn{1}{l}{6} \\
\hline Trial 1 & $5 \cdot 2(2 \cdot 0)$ & $11 \cdot 0(8 \cdot 1)$ & $11 \cdot 4(5 \cdot 9)$ \\
Trial 2 & $6 \cdot 0(2 \cdot 8)$ & $7.8(3.0)$ & $8.9(4 \cdot 3)$ \\
Total & $5 \cdot 6(2 \cdot 4)$ & $9 \cdot 4(6.3)$ & $10 \cdot 2(5 \cdot 3)$ \\
\hline
\end{tabular}

*Mean response time (SD) for each word length in each trial $(\mathrm{n}$ per cell $=24)$.

\section{WORD READING}


was very satisfactory albeit slow. She read correctly $19 / 20$ three-letter non-words-for example, wib, dep, 18/18 four-letter nonwords (nusk, beld), and 4/4 five-letter nonwords (dreed, bleam). This establishes that her ability to transcode from print to sound is unimpaired.

\section{SCRIPT READING}

Twenty printed eight-letter words and 20 different eight-letter script words (Letraset no. 520,28 point and no. 279,36 point) were presented singly. The time to read each word was recorded by a stopwatch. All words except the script word anecdote were read correctly. The mean reading time for each print word was $11.9 \mathrm{~s}$ which is very similar to the times recorded in the word reading task. Her mean time to read script words was $24.8 \mathrm{~s}$ which is more than twice as long as for printed words. For the patient, script word reading was considerably more difficult than print word reading.

\section{TACHISTOSCOPIC READING}

Tachistoscopic reading forces 'whole' word reading with exposure durations that are too brief to permit a letter by letter strategy. Her ability to read words presented using brief exposure durations (500 ms) was assessed using a Cambridge tachistoscope (model CT2).

For the first task, 24 three-letter words and 25 three-letter non-words, such as bev and tas, were presented in random order. She was first asked to categorise the letter strings as a word or non-word and then to report the constituent letters. She was encouraged to guess if uncertain. Ten words (and 52 of their constituent letters) and eight non-words (49 of their constituent letters) were reported correctly. She was only able to categorise correctly 14 of the 31 words and non-words that could not be read. There is thus no evidence of a 'real' word gain or lexical effect on this task.

For the second task, 12 common inanimate object names and 12 animal names matched for word length and frequency were presented singly in random order. After each presentation she was asked, Is it an animal? This categorisation task was replicated three times and on each occasion she obtained a chance score $(12 / 24,13 / 24$, and $13 / 24$ correct respectively).

For the third task, 25 boys' names and 25 girls' names, which she was required to read and categorise, were presented in random order. She failed to read any of the names and she scored $28 / 50$ correct on the categorisation task: again a chance score.

Table 2 The detection of 'rogue' letters at the beginnings and ends of words

\begin{tabular}{|c|c|c|c|c|}
\hline & \multicolumn{2}{|c|}{$M R T$ for beginning of word $(s)^{\star}$} & \multicolumn{2}{|c|}{$M R T$ for end of word $(s)^{\star}$} \\
\hline & 'Legal' & 'Illegal' & 'Legal' & 'Illegal' \\
\hline $\begin{array}{l}\text { Trial } 1 \\
\text { Trial } 2\end{array}$ & $\begin{array}{l}16 \cdot 2(10 \cdot 2) \\
15 \cdot 0(13 \cdot 9)\end{array}$ & $\begin{array}{l}27 \cdot 9(21 \cdot 2) \\
15 \cdot 2(12 \cdot 5)\end{array}$ & $\begin{array}{l}22 \cdot 9(24 \cdot 1) \\
14 \cdot 9(17 \cdot 3)\end{array}$ & $\begin{array}{l}17 \cdot 1(9 \cdot 9) \\
15 \cdot 9(11 \cdot 6)\end{array}$ \\
\hline
\end{tabular}

ॠMean response time $(\mathrm{SD})$ for each word length in each trial $(\mathrm{n}$ per cell $=24$ ).
The findings of these three tasks demonstrate that her ability to categorise words presented tachistoscopically is very impaired and that she does not even have partial knowledge of words presented too quickly to be read letter by letter.

\section{INVESTIGATION OF READING \\ Lexical decision}

This test manipulated orthographic constraints in a lexical decision task. The stimuli consisted of three types of letter strings: 19 common three-letter words, such as pen, car, 19 pronounceable three-letter non-words (cal, fot) and 19 three-letter non-pronounceable letter strings, (rks, isr). The stimuli were typed singly on index cards in lower case and presented in random order for unlimited time across the desk. The patient was asked, Is it a word? and her response was timed by a stopwatch. The mean response time for each type of letter string was $4.8 \mathrm{~s}$ (real words), 6.8 s ('legal' non-words) and $4 \cdot 2 \mathrm{~s}$ ('illegal' nonwords). Her overall error rate was very low (55/57 correct). Her response rate was comparable to that observed in reading aloud (table 2). There was no difference in lexical decision time for words and illegal nonwords. She took significantly longer (MannWhitney U test, $\mathrm{z}=79.5, \mathrm{p}<0.01$ ) to decide that orthographically legal letter combinations were non-words. This demonstrates a normal increase in reaction time for a no response.

\section{WORD DETECTION}

In this test we assessed whether word detection is affected by additional letters. The stimuli consisted of 60 common nouns to which an extra 'rogue' letter had been added either at the beginning of the word or at the end of the word. An 'illegal' letter combination was used (ywatch, sheepr) for 30 and a 'legal' letter combination (truler, threet) for 30 of the stimulus words. For each type of letter combination, 15 were at the beginning and 15 at the end of the word. There were an equal number of words of three, four or five letters in each of the four conditions. The stimulus words were typed in lower case on index cards and presented singly in randomised order for unlimited time across the desk. The patient was asked to cross out the 'rogue' letter with a red ballpoint pen as quickly as possible. This test was attempted on two occasions.

Table 2 gives the mean response times for each condition on each trial. The overall error rate was very low indeed but her response times were slow and very variable. There were no significant effects of letter position or letter legality. She proceeded by a very laborious process of trial and error 'spelling' out different letter combinations until she detected the stimulus word. This process took considerably longer than reading aloud words of comparable length (see table 1).

PARSING WORD STRINGS

It has been demonstrated that a letter string consisting of three unspaced words such as 
orangeredchicken can be parsed and read aloud by a patient with a transcortical sensory aphasic syndrome, with virtually no capacity to comprehend either the written or the spoken word. McCarthy and Warrington ${ }^{16}$ argued that the integrity of the visual word form was necessary to parse the letter strings into their constituent words and that this provided evidence of presemantic lexical processing.

The patient attempted a similar task of parsing three word letter strings by marking the boundaries between the words. She failed completely on this task. After numerous attempts with different letter strings she had not produced one correct solution. Indeed, she took up to three minutes to split the first two words. The task was therefore simplified by asking her to mark the boundary between two unspaced words.

The stimuli consisted of 48 unspaced word pairs: words of four, five or six letters were paired, such that the combined length was 10 letters - that is $5+5,4+6,6+4)$. Twelve pairs of high frequency words were of the same category, (such as applepeach), 12 pairs were semantically related (fieldsheep) and 24 pairs were unrelated words (grasstrain). The patient was required to mark the boundary between the two words with a red ballpoint pen.

Table 3 shows the mean response times for each condition. She was able to detect the boundary between the word pairs slowly but accurately. Her response times were very variable but with persistence she was able to complete this task. The task apparently stretched her strategy of letter by letter reading to the limit. The patient's reading which was at all times laborious was even further disrupted by this task. Additionally there was no evidence of any semantic facilitation in so far as she was as slow with the semantically related pairs as the unrelated pairs.

\section{INTERPOLATED LETTERS}

It has been demonstrated that distortion of the orthography of the printed word by interpolating extraneous letters can be very disruptive of whole word reading in normal subjects (McCarthy, unpublished observations). One patient with transcortical sensory aphasia, investigated by McCarthy and Warrington, was able to read regular words at a normal speed and to parse word strings (see above). ${ }^{17}$ Like normal subjects, however, this

Table 3 Parsing unspaced word strings into their constituent words

\begin{tabular}{llll}
\hline Stimuli (two words) & Same category & Semantic association & Unrelated \\
\hline Number of word pairs & 12 & 12 & 24 \\
Errors & 0 & 0 & 1 \\
Mean response time (SD) (s) & $16 \cdot 8(12 \cdot 0)$ & $22 \cdot 3(15 \cdot 2)$ & $14 \cdot 5(9 \cdot 2)$ \\
\hline
\end{tabular}

Table 4 Reading words with extraneous interpolated letters

\begin{tabular}{llll}
\hline & $\begin{array}{l}\text { Control } \\
n=30\end{array}$ & $\begin{array}{l}\text { Interpolated letters } \\
n=30\end{array}$ & $\begin{array}{l}\text { Interpolated asterisks } \\
n=30\end{array}$ \\
\hline $\begin{array}{l}\text { Mean response time (SD) to } \\
\text { read aloud the stimulus word } \\
\text { in each condition }\end{array}$ & $7 \cdot 3(4 \cdot 9)$ & $7 \cdot 6(4 \cdot 1)$ & $9 \cdot 6(4 \cdot 5)$ \\
\hline
\end{tabular}

patient resorted to letter by letter reading and made multiple errors in attempting to read short words typed in black that had randomly selected red letters printed between each adjacent letters of the word (denoted here by emboldened type-for example, QrUnIyCeK, DkAbNaCmE).

Our patient attempted a similar task. Fifteen four-letter words and 15 five-letter high frequency words were selected. These 30 words were (a) typed conventionally in upper case, (b) with a red asterisk between each letter-for example, $B \star R^{\star} A \star V \star E$, and (c) with the letters of a second word typed in red lower case interspersed (BbRaAkVeE). Each condition was tested in blocks of 10 words using a Latin square design. Her error rate was very low (88/90 correct). Table 4 gives the mean time to read each word in each condition. The times to read aloud the words in the critical conditions, the control as compared with the interpolated letters, were obviously not significantly different; nor did splitting the word with asterisks have a significant interference effect (Mann-Whitney $U$ test, $z=1 \cdot 6, p>0 \cdot 1)$. Our patient, unlike normal subjects and the patient previously described, was very little disrupted by this manipulation of the orthography of the word. Individual letter processing was sufficiently efficient to be virtually immune to the effects of adjacent interfering letters.

\section{Discussion}

We have established that our patient is a classical spelling dyslexic who reads letter-by-letter. ${ }^{17}$ Her writing and spelling were excellent. Her performance on tests of letter naming was intact whether they were presented singly or in arrays. The time she took to read words was directly related to their length. She had greater difficulty in reading script than print. Her ability to read words that were presented for a brief tachistoscopic exposure was exceptionally bad. We would assume that both our patient and other pure examples of this syndrome have a reading specific deficit. In this context we would emphasise the dissociation between the ability to name letters and arrays of letters (which were read quite normally) and the impairment of whole word reading.

In the tachistoscopic tasks there was no evidence of even crude comprehension of words that could not be read and there was no evidence of partial semantic knowledge. She failed to categorise object names as living or inanimate, and had equal difficulty in categorising boys' and girls' names. These are typical features of dyslexics whose semantic analysis of the written word is faulty. ${ }^{28}$ More important, it has been established that a patient with virtually no comprehension of the written word, but with intact phonology, can read aloud at a normal speed. Our evidence indicates that our patient has intact phonology. Like the patient in the McCarthy and Warrington study, ${ }^{17}$ who had transcortical sensory aphasia with gravely impaired comprehension of the written word, our 
patient is able to read aloud non-words competently. But she, unlike the previous patient, is unable to read at a normal speed using phonological procedures. It therefore follows that her deficit must arise before semantic and phonological analysis.

There remain two plausible candidates: damage to an input stage in the word reading process before accessing a visual word form; and damage to the visual word form system itself. The typical characteristics of the pure letter by letter reading syndrome, word length, a script and exposure duration effect are all entirely consistent with the disrupted word form hypothesis. But equally, these effects do not differentiate between a degradation of the representations in a word form system, and the input procedures to that system. In an attempt to address this issue, we have focused on assessing her orthographic recognition capacities. If her deficit implicated a degradation within the word form system, one would predict that her performance would be disproportionately disrupted on reading tasks that demand its integrity. If this were not the case, however, then reading tasks that maximise the operation of a word form system should not present additional difficulty.

Her performance on the lexical decision task was slow. Indeed she took as long to make the lexical decision as to read aloud a word letter by letter. There did not appear to be a significant gain with the non-pronounceable letter trials when a no response should be possible after processing the first two letters of the trigram.

Our patient had great difficulty in detecting a 'rogue' letter placed at the beginning or end of a real word, some of which created 'legal' and some 'illegal' letter combinations. Not only was her performance particularly slow on this task, there was no influence on the type or the position of the 'rogue' letter on her speed. This is entirely consistent with the notion that the person with spelling dyslexia bypasses the damaged word form system and resorts to an indirect reverse spelling strategy. But it is less clear how it could be accommodated by an input position. We would suggest that a 'rogue' letter stretches a reverse spelling strategy to the limit. Our patient appeared to solve the task by repeatedly reading the letter string (albeit accurately) until a real word solution was detected.

When the 'rogue' letters were clearly signalled by a colour change, however, a very different result was obtained. The manipulation of interpolating extraneous letters in a word has a dramatically disruptive effect on normal readers. Indeed they become letter by letter readers and show word length effects (McCarthy, unpublished observations). Our patient was unaffected by this orthographic manipulation. In fact her performance could be regarded as supranormal. One would predict on the serial input model that interpolated letters in a word would have a very significant disruptive effect.
Our patient was unable to cope with the task demands of marking the boundaries of a row of three words printed without the conventional spaces. On the much easier task of marking the boundary between two words without any requirement to read the word aloud she was significantly slow. According to a serial input model, one might expect that the strategy of reading slowly letter by letter should be able to complete this task at least as quickly as reading aloud words of the same length.

Overall we have been impressed by the absence of any lexical effects together with the particular difficulty our patient experienced in tackling the simple, clinically administered tasks that disrupt letter by letter reading. We would argue that these manipulations overload a reverse spelling strategy. At any rate, our patient was reduced to repetitive trial and error on these tasks, and her normally slow but accurate reading all but disintegrated. At the same time she was immune to a simple manipulation that reduces the normal reader to letter by letter reading. These observations are, we suggest, difficult to reconcile with a deficit of input, to a word form system, that is, itself intact.

Rather we propose that these findings provide direct evidence that, for our patient, there has been damage to the visual word form system and that her letter by letter reading is a strategy to overcome a lexical loss. Accepting that letter by letter reading is a strategy resorted to when normal reading is no longer possible, one would then predict some degree of heterogeneity of this type of acquired dyslexia. Although in this case we would argue that the locus of deficit is the word form system itself, we would not wish to generalise this interpretation to all other cases. The core deficit in other cases could well be either prelexical or at a later stage in the reading process.

There have been relatively few cases reported in whom there was both a well localised lesion and a relatively pure spelling dyslexia. To our knowledge, however, in every case, including our patient, a lesion was demonstrated in the occipitoparietal region in the left hemisphere. ${ }^{391920}$

We are grateful to Professor W I McDonald for permission to test ROC, a patient under his care and to report our findings. We thank Frances Clegg and Jane McNeil for their assistance in testing the patient and Rosaleen McCarthy and Dr Peter Rudge for their advice in the preparation of this manuscript.

1 Dejerine J. Contribution a l'étude anatomoclinique et clinique des différentes variétés de cécité verbal. $C R$ Soc Biol (Paris) 1892;4:61-90.

2 Shallice T. From neuropsychology to mental structure. New York: Cambridge University Press, 1988.

3 Warrington EK, Shallice T. Word form dyslexia. Brain 1980;103:99-112.

4 Patterson K, Kay J. Letter-by-letter reading: Psychological descriptions of a neurological syndrome. Qf Exp Psychol $A$ 1982;34:411-41.

5 Schacter DL, Rapscak SZ, Rubens AB, Tharan $M$, Laguna J. Priming effects in a letter-by-letter reader depend upon access to the word form system. 28:1079-94

6 Friedman RB, Alexander MP. Pictures, images, and pure alexia: A case study. Cogn Neuropsychol 1984;1:9-23. 
7 Farah MJ, Wallace MA. Pure alexia as a visual impairment: A reconsideration. Cogn Neuropsychol 1991;8: 313-34.

8 Warrington EK. Visual deficits associated with occipital lobe lesions in man. Exp Brain Res 1986;11 (suppl.) 247-61.

9 Shallice T, Saffran EM. Lexical processing in the absence of explicit word identifications: Evidence from a letterby-letter reader. Cogn Neuropsychol 1986;3:429-58.

10 Coslett HB, Saffran EM. Evidence for preserved reading in 'Pure Alexia'. Brain 1989;112:327-59.

11 McKenna P, Warrington EK. The graded naming test. Windsor, UK: NFER-Nelson, 1983.

12 Coughlan AK, Warrington EK. Word-comprehension and word-retrieval in patients with localised cerebral lesions. word-retrieval in patients
Brain 1978;101:163-85.

13 Baxter-Versi DM. Acquired spelling disorders. Ph D Thesis,
University of London, 1987

14 Willison JR, Warrington EK. Cognitive retardation in a patient with preservation of psychomotor speed. Behav Neurol 1992;5:113-6.

15 Burt C. Handbook of tests for use in schools. London: Staples Press, 1923.

16 McCarthy RA, Warrington EK. Phonological reading. Phenomena and paradoxes. Cortex 1986;22:359-80

17 McCarthy RA, Warrington EK. Cognitive neuropsychology. New York: Academic Press, 1990.

18 Warrington EK, Shallice T. Semantic access dyslexia. Brain 1979;102:43-63.

19 Kinsbourne M, Warrington EK. A disorder of simultaneous form perception. Brain 1962;85:461-86.

20 Kinsbourne M, Warrington EK. The localizing significance of limited simultaneous form perception. Brain 1963;85:697-702.
Sir Jonathan Hutchinson (1828-1913) and an early description of temporal arteritis

The subject ... was an old man ... the father of a well remembered beadle at the London Hospital College 30 years ago. ... I was asked to see him because he had "red streaks on his head" which were painful and prevented his wearing his hat. The "red streaks" proved to be his temporal arteries which... were inflamed and swollen. Pulsation could be feebly detected in the affected vessel, but it finally ceased; the redness then subsided, and the vessels were left impervious cords. The old gentleman lived, I believe, several years after this without any other manifestation of arterial disease". 1

Although headache does not figure prominently in Hutchinson's description, the inflammatory signs are unmistakable. Widespread recognition succeeded the 1934 paper of Horton, Magath, and Brown. ${ }^{2}$

Hutchinson was born in Selby and with his friend Hughlings Jackson, studied at the York School of Medicine and Surgery, proceeding to St Bartholomew's, London, in 1849, qualifying MRCS and LSA in 1850 . He was appointed to the London Hospital Medical College in 1862 and became FRS in 1882. His fame earned him honorary degrees from the
Universities of Glasgow, Cambridge, Edinburgh, Oxford, Dublin, and Leeds. He was knighted in 1908.

Hutchinson was, like his associate Thomas Hodgkin (1798-1866), a devout Quaker, who lectured on Sunday afternoons at the meeting house near his home in Haslemere, Surrey, where he housed a library and museum. Few doctors have been so versatile; he practised as surgeon, ophthalmologist, neurologist and dermatologist. He wrote the 10 volume Archives of Surgery (1885-99) a remarkable singlehanded labour. But he is most remembered for his studies on syphilis based on more than a million patients, and for the notched, short, narrow, central upper incisor permanent teeth of congenital syphilitics-Hutchinson's teeth ${ }^{3}$ - and for the fixed dilated pupil of temporal lobe coning-Hutchinson's pupil. JMS PEARCE 304 Beverley Road, Anlaby, Hull

1 Hutchinson J. Diseases of the arteries. Arch Surg 1890; 1:323-33.

2 Horton BT, Magath TB, Brown GE. Arteritis of the temporal vessels. Arch Intern Med 1934;53:400-9.

3 Hutchinson J. Clinical lecture on heredito-syphilitic $1861 ; 1: 515-7$. 